\title{
Evaluation of Metal Phosphide Nanocrystals as Anode Materials for Na-ion Batteries
}

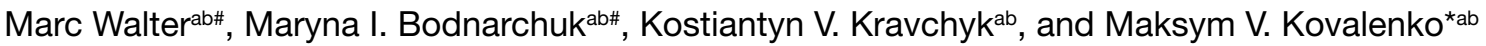

\begin{abstract}
Sodium-ion batteries (SIBs) are potential low-cost alternatives to lithium-ion batteries (LIBs) because of the much greater natural abundance of sodium salts. However, developing high-performance electrode materials for SIBs is a challenging task, especially due to the $\sim 50 \%$ larger ionic radius of the $\mathrm{Na}^{+}$ion compared to $\mathrm{Li}^{+}$, leading to vastly different electrochemical behavior. Metal phosphides such as $\mathrm{FeP}, \mathrm{CoP}, \mathrm{NiP}_{2}$, and $\mathrm{CuP}_{2}$ remain unexplored as electrode materials for SIBs, despite their high theoretical charge storage capacities of 900-1300 mAh g-1. Here we report on the synthesis of metal phosphide nanocrystals (NCs) and discuss their electrochemical properties as anode materials for SIBs, as well as for LIBs. We also compare the electrochemical characteristics of phosphides with their corresponding sulfides, using the environmentally benign iron compounds, $\mathrm{FeP}$ and $\mathrm{FeS}_{2}$, as a case study. We show that despite the appealing initial charge storage capacities of up to $1200 \mathrm{mAh} \mathrm{g}^{-1}$, enabled by effective nanosizing of the active electrode materials, further work toward optimization of the electrode/electrolyte pair is needed to improve the electrochemical performance upon cycling.
\end{abstract}

Keywords: Anode materials $\cdot \mathrm{Li}$-ion batteries $\cdot$ Na-ion batteries $\cdot$ Nanocrystals $\cdot$ Synthesis

\section{Introduction}

Lithium-ion batteries (LIBs) have become the battery technology of choice for applications demanding high energy and power densities, such as portable electronics and electric vehicles, and also show great promise for the large-scale grid storage of electricity. Yet, the irregular geographic distribution and relatively low natural abundance of lithium salts raise doubts as to the future security and cost of supply. In this regard, conceptually identical sodium-ion batteries (SIBs) are a favorable alternative due to the much greater abundance (by a factor of $10^{3}$ ) and therefore lower price of sodium salts. ${ }^{[1]}$ However, the seemingly simple replacement

\footnotetext{
${ }^{\star}$ Correspondence: Prof. Dr. M. Kovalenko ${ }^{\text {ab }}$

E-mail: mvkovalenko@ethz.ch;

Maksy.Kovalenko@empa.ch

${ }^{a}$ ETH Zürich

Laboratory of Inorganic Chemistry

Department of Chemistry and Applied Biosciences

$\mathrm{HCl} \mathrm{H} 139$

Vladimir-Prelog-Weg 1

$\mathrm{CH}-8093$ Zurich

bEMPA - Swiss Federal Laboratories for

Materials Science and Technology

Laboratory for thin films and photovoltaics

Überlandstrasse 129

$\mathrm{CH}-8600$ Dübendorf

\#These authors contributed equally to this work
}

of the $\mathrm{Li}^{+}$ion with its $50 \%$ larger group I neighbor has drastic consequences for the resulting electrochemistry. For instance, both silicon and graphite, which are wellknown anode materials with outstanding lithium ion storage properties, show negligible capacities for sodium ions. ${ }^{[2]}$ Extensive research toward new electrode materials is needed to advance the development of high-performance SIBs.

Of all possible anode materials for SIBs, red phosphorus $(\mathrm{P})$ is probably the most appealing candidate due to its low cost, nontoxicity and, most importantly, extremely high sodium capacity (2596 $\mathrm{mAh} \mathrm{g}^{-1}$ for $\mathrm{P} \leftrightarrow \mathrm{Na}_{3} \mathrm{P}$, the highest $\mathrm{Na}^{+}$ capacity known) at a low desodiation potential $\left(\sim 0.6 \mathrm{~V}\right.$ vs. $\left.\mathrm{Na}^{+} / \mathrm{Na}\right)$. However, similarly to other alloying/conversion type materials, $\mathrm{P}$ suffers from massive volume changes during sodiation/desodiation $(\Delta V$ $=291 \%$, by molar volume) leading to the mechanical disintegration of the electrodes and therefore rapid capacity fading due to loss of electrical contact. The other main disadvantage of $\mathrm{P}$ is its relatively low electronic conductivity, causing slow reaction kinetics. Although noticeable progress has been demonstrated for P-based SIB anodes, ${ }^{[3]}$ typically very large amounts of conductive carbons are used to provide sufficient conductivity as well as mechanical stability of the electrodes, and often high capacities with good cycling stability can only be achieved at low charge/discharge currents of $\sim 100 \mathrm{~mA} \mathrm{~g}^{-1}(\sim 0.05 \mathrm{C})$.
In this study, we were intrigued by the possibility of addressing the aforementioned issues facing P-based SIB anodes by using metal phosphide nanocrystals (NCs) as the active material. Generally, nanostructured materials often show improved electrochemical performance over their bulk counterparts due to mitigation of the effects caused by volumetric changes and improved ionic and electronic conductivities upon homogeneous mixing with conductive carbon additives. ${ }^{[4]}$ Moreover, metallic inclusions, which form in situ upon electrochemical conversion of the transition metal phosphide to alkali metal phosphide, are also expected to improve the electronic connectivity within the electrode. Despite the additional mass of the transition metal, theoretical specific charge-storage capacities of metal phosphides are still extremely high (900-1300 $\mathrm{mAh} \mathrm{g}^{-1}$ ), surpassing all of the main alternatives to $\mathrm{P}$ such as $\mathrm{Sn}\left(847 \mathrm{mAh} \mathrm{g}^{-1}\right)$ and $\mathrm{Sb}\left(660 \mathrm{mAh} \mathrm{g}^{-1}\right)$. Herein, we present the sodium and also lithium storage properties of highly uniform $\mathrm{FeP}, \mathrm{CoP}, \mathrm{NiP}_{2}$ and $\mathrm{CuP}_{2}$ NCs prepared via colloidal synthesis methods. It should be noted that, with the exception of a recent study on FeP, ${ }^{[5]}$ this is the first report on the electrochemical performance of such metal phosphides in SIBs. All of the phosphide NCs investigated in this work show high charge-storage capacities, close to the theoretically expected values. In comparison to the corresponding metal sulphide $\mathrm{NCs}$, the phosphides 
exhibit lower desodiation potentials and are hence better suited as SIB anode materials, but suffer from very fast capacity loss upon cycling. Further work on the optimized formulation of the electrodes and the selection of suitable electrolytes and electrolyte additives is needed to improve long-term cycling stability.

\section{Experimental}

\subsection{Synthesis of Metal Phosphide Nanocrystals}

\subsubsection{FeP Nanowires (NWs)}

In a typical experiment, $2.5 \mathrm{~g}$ tri- $\mathrm{n}$ octylphosphine oxide (TOPO, 99\%, Strem) and $3 \mathrm{~mL}$ tri-n-octylphosphine (TOP, $\geq 97 \%$, Strem), previously dried at $100{ }^{\circ} \mathrm{C}$ under vacuum for $1 \mathrm{~h}$, were heated to $300{ }^{\circ} \mathrm{C}$ under Ar. At $300{ }^{\circ} \mathrm{C}, 0.5 \mathrm{~mL}$ of Fe stock solution, prepared by mixing 1 $\mathrm{mL}$ TOP and $0.25 \mathrm{~mL} \mathrm{Fe}(\mathrm{CO})_{5}(99.99 \%$, Strem), was injected into the TOP/TOPO mixture. After $30 \mathrm{~min}$, a second injection of $0.5 \mathrm{~mL}$ of stock solution was carried out. The reaction was stopped after an additional 30 min. FeP NWs were precipitated by adding hexane and ethanol, separated by centrifugation, and re-dispersed in chloroform containing $1 \mathrm{wt} \%$ oleic acid. The second precipitation was induced by adding ethanol. After centrifugation, the FeP nanowires were re-dispersed in chloroform and stored under ambient conditions.

\subsection{2 $\mathrm{NiP}_{2} \mathrm{NCs}$}

In a typical experiment, $4.5 \mathrm{~mL}$ octadecene (ODE, 90\%, Sigma-Aldrich), $6.4 \mathrm{~mL}$ oleylamine (OLA, 95\%, Strem) and $0.25 \mathrm{~g}(1 \mathrm{mmol})$ nickel(II) acetylacetonate $\left(\geq 98 \%\right.$, Merck) were dried at $110^{\circ} \mathrm{C}$ under vacuum for $1 \mathrm{~h}$ to remove water and low-boiling point impurities. Then, $2 \mathrm{~mL}$ of TOP were added to the flask under $\mathrm{Ar}$ and the reaction mixture was heated to $320{ }^{\circ} \mathrm{C}$ and held at this temperature for $1 \mathrm{~h}$. The flask was cooled to $200{ }^{\circ} \mathrm{C}$ by flowing air and then $105 \mathrm{mg}$ (3.4 mmol) of red phosphorous ( $\geq 97 \%$, Sigma-Aldrich) were added. The reaction mixture was then heated again to $330{ }^{\circ} \mathrm{C}$ and held at this temperature for $22 \mathrm{~h}$. $\mathrm{NiP}_{2} \mathrm{NCs}$ were precipitated twice by adding chloroform and ethanol, separated by centrifugation, and re-dispersed again in chloroform. After centrifugation, the $\mathrm{NiP}_{2} \mathrm{NPs}$ were redispersed in chloroform and stored under ambient conditions.

\subsubsection{CoP NCs}

In a typical experiment, $4.5 \mathrm{~mL}$ ODE, $6.4 \mathrm{~mL}$ OLA and $0.25 \mathrm{~g}$ ( $1 \mathrm{mmol})$ cobalt(II) acetylacetonate ( $\geq 98 \%$, Merck) were dried at $110{ }^{\circ} \mathrm{C}$ under vacuum for $1 \mathrm{~h}$ to remove water and low-boiling point impurities.
Then, $2 \mathrm{~mL}$ of TOP were added to the flask under $\mathrm{Ar}$ and the reaction mixture was heated to $320^{\circ} \mathrm{C}$ for $65 \mathrm{~min}$. The flask was cooled to $200{ }^{\circ} \mathrm{C}$ by flowing air and then $105 \mathrm{mg}$ ( $3.4 \mathrm{mmol})$ of red phosphorous were added. Then the reaction mixture was heated again to $330{ }^{\circ} \mathrm{C}$ and held at this temperature for $22 \mathrm{~h}$. CoP NCs were isolated and purified identically to the $\mathrm{NiP}_{2}$ NCs above.

\subsubsection{CuP ${ }_{2}$ NCs}

In a typical experiment, $4.5 \mathrm{~mL}$ ODE, $6.4 \mathrm{~mL}$ OLA and $0.262 \mathrm{~g}(1 \mathrm{mmol})$ copper(II) acetylacetonate ( $\geq 97 \%$, SigmaAldrich) were dried at $110{ }^{\circ} \mathrm{C}$ under vacuum for $1 \mathrm{~h}$ to remove water and low-boiling point impurities. Then, $2 \mathrm{~mL}$ of TOP were added to the flask under Ar atmosphere and the reaction mixture was heated to $320^{\circ} \mathrm{C}$ for $75 \mathrm{~min}$. The flask was cooled to $200^{\circ} \mathrm{C}$ by flowing air and then $200 \mathrm{mg}(6.4 \mathrm{mmol})$ of red phosphorous were added. The reaction mixture was then heated again to $330{ }^{\circ} \mathrm{C}$ and was held at this temperature for $22 \mathrm{~h}$. CuP $\mathrm{NCs}$ were isolated and purified identically to the $\mathrm{NiP}_{2} \mathrm{NCs}$ above.

\subsection{Characterization of Metal Phosphide Nanocrystals}

Transmission electron microscopy (TEM) was performed using a JEOL JEM$2200 \mathrm{FS}$ instrument operated at $200 \mathrm{kV}$, using carbon-coated $\mathrm{Cu}$ grids as substrates (Ted-Pella). Powder X-ray diffraction (XRD) was measured using a STOE STADI P diffractometer (with $\mathrm{Cu}-\mathrm{K} \alpha_{1}$ irradiation, $\lambda=1.540598 \AA$ ).

\subsection{Electrode Preparation, Cell Assembly and Electrochemical Measurements}

In order to evaluate the electrochemical properties of $\mathrm{FeP}, \mathrm{CoP}, \mathrm{NiP}_{2}$ and $\mathrm{CuP}_{2}$ $\mathrm{NCs}, \mathrm{Na}$-ion and Li-ion half-cells were assembled. Prior to electrode preparation, organic ligands were removed from the surface of the NCs by stirring them in a $1 \mathrm{M}$ solution of hydrazine in acetonitrile for $2 \mathrm{~h}$ at room temperature, as is commonly performed for colloidal quantum dots. ${ }^{[6]}$ Electrodes were prepared by mixing the respective metal phosphide NCs (63.75 wt\%) with carbon black (21.25 wt \%, TIMCAL), carboxymethylcellulose (CMC, $15 \mathrm{wt} \%$ ) and water as a solvent using a planetary ball-mill at $500 \mathrm{rpm}$ for $1 \mathrm{~h}$. The aqueous slurries were coated onto $\mathrm{Cu}$ current collectors, which were dried at $80{ }^{\circ} \mathrm{C}$ under vacuum overnight prior to cell assembly. For electrochemical testing, coin cells with elemental $\mathrm{Na}$ or $\mathrm{Li}$ were assembled in an Ar-filled glovebox $\left(\mathrm{O}_{2}<0.1 \mathrm{ppm}, \mathrm{H}_{2} \mathrm{O}<\right.$ $0.1 \mathrm{ppm}$ ) using either $1 \mathrm{M} \mathrm{NaClO}_{4}$ in propylene carbonate (PC) with $10 \%$ fluoroethylene carbonate (FEC) or $1 \mathrm{M} \mathrm{LiPF}_{6}$ in a 1:1 mixture of ethylene carbonate (EC) and dimethyl carbonate (DMC) with 3\% FEC. FEC was added to the electrolyte in both the $\mathrm{Li}$ and $\mathrm{Na}$ coin cells to improve capacity retention. ${ }^{[3 \mathrm{c}, 7]}$ All electrochemical tests were carried out at room temperature and the capacities were reported relative to the mass of the metal phosphide NCs.

\section{Results and Discussion}

\subsection{Synthesis and Characterization of Metal Phosphide Nanocrystals}

FeP NWs were synthesized according to the procedure reported by Qian et al. ${ }^{[8]}$ In order to obtain $\mathrm{NiP}_{2} \mathrm{NCs}$, a two-step procedure was developed. First, $\mathrm{Ni}_{2} \mathrm{P}$ NCs were synthesized according to a known protocol reported by Popczun et al. ${ }^{[9]} \mathrm{We}$ then added a second step: conversion of the as-prepared $\mathrm{Ni}_{2} \mathrm{P}$ NCs into $\mathrm{NiP}_{2} \mathrm{NCs}$ by adding red $\mathrm{P}$ to the reaction mixture, followed by heating at $330{ }^{\circ} \mathrm{C}$ for $22 \mathrm{~h}$. Analogously, this two-step approach was also applied in the synthesis of $\mathrm{CuP}_{2}$ and $\mathrm{CoP}$ NCs, simply by replacing nickel(II) acetylacetonate with the respective copper or cobalt salt (for details, see the Experimental section). Fig. 1 summarizes the characterization of the metal phosphide NCs obtained by these methods. FeP NCs were on average $\sim 300 \mathrm{~nm}$ in length and $\sim 7 \mathrm{~nm}$ in width. $\mathrm{CoP}, \mathrm{NiP}_{2}$ and $\mathrm{CuP}_{2} \mathrm{NCs}$ exhibited diameters of 25,10 and $60 \mathrm{~nm}$, respectively. All materials showed phase-pure XRD patterns, indexed according to the standard ICSD files for these compounds.

\subsection{Electrochemical Performance of Metal Phosphide Nanocrystals}

Fig. 2 shows the electrochemical performance of the metal phosphide NCs in $\mathrm{Na}$-ion and Li-ion half-cells. Na-ion cells were cycled at a current rate of $100 \mathrm{~mA} \mathrm{~g}^{-1}$ in the potential range of $0.02-2.5 \mathrm{~V}$. For Liion cells, current rates of $300 \mathrm{~mA} \mathrm{~g}^{-1}$ and a potential range of $0.02-2.0 \mathrm{~V}$ were used. Assuming the formation of $\mathrm{Na}_{3} \mathrm{P}$ or $\mathrm{Li}_{3} \mathrm{P}$ via the general conversion reaction

$\mathrm{MP} \times+3 \times \mathrm{e}^{-}+3 \times \mathrm{A}^{+} \leftrightarrow \times \mathrm{A}_{3} \mathrm{P}+\mathrm{M}$

$(\mathrm{M}=\mathrm{Fe}, \mathrm{Co}, \mathrm{Ni}, \mathrm{Cu} ; \mathrm{A}=\mathrm{Li}, \mathrm{Na})$,

the metal phosphides $\mathrm{FeP}, \mathrm{CoP}, \mathrm{NiP}_{2}$ and $\mathrm{CuP}_{2}$ have theoretical capacities of 926 , 894,1333 and $1282 \mathrm{mAh} \mathrm{g}^{-1}$, respectively. In close agreement, $\mathrm{CuP}_{2}$ indeed showed the highest capacity in the first cycle. However, the capacities of all studied materials rapidly faded during cycling. The compounds with higher $\mathrm{P}$ content, $\mathrm{NiP}_{2}$ and $\mathrm{CuP}_{2}$, showed higher initial capacities but poorer capacity retention. Namely, for $\mathrm{CuP}_{2}$ NCs the charge capacity decreased from $1140 \mathrm{mAh} \mathrm{g}^{-1}$ to $570 \mathrm{mAh} \mathrm{g}^{-1}$ within the first 16 cycles. For the FeP, CoP and 

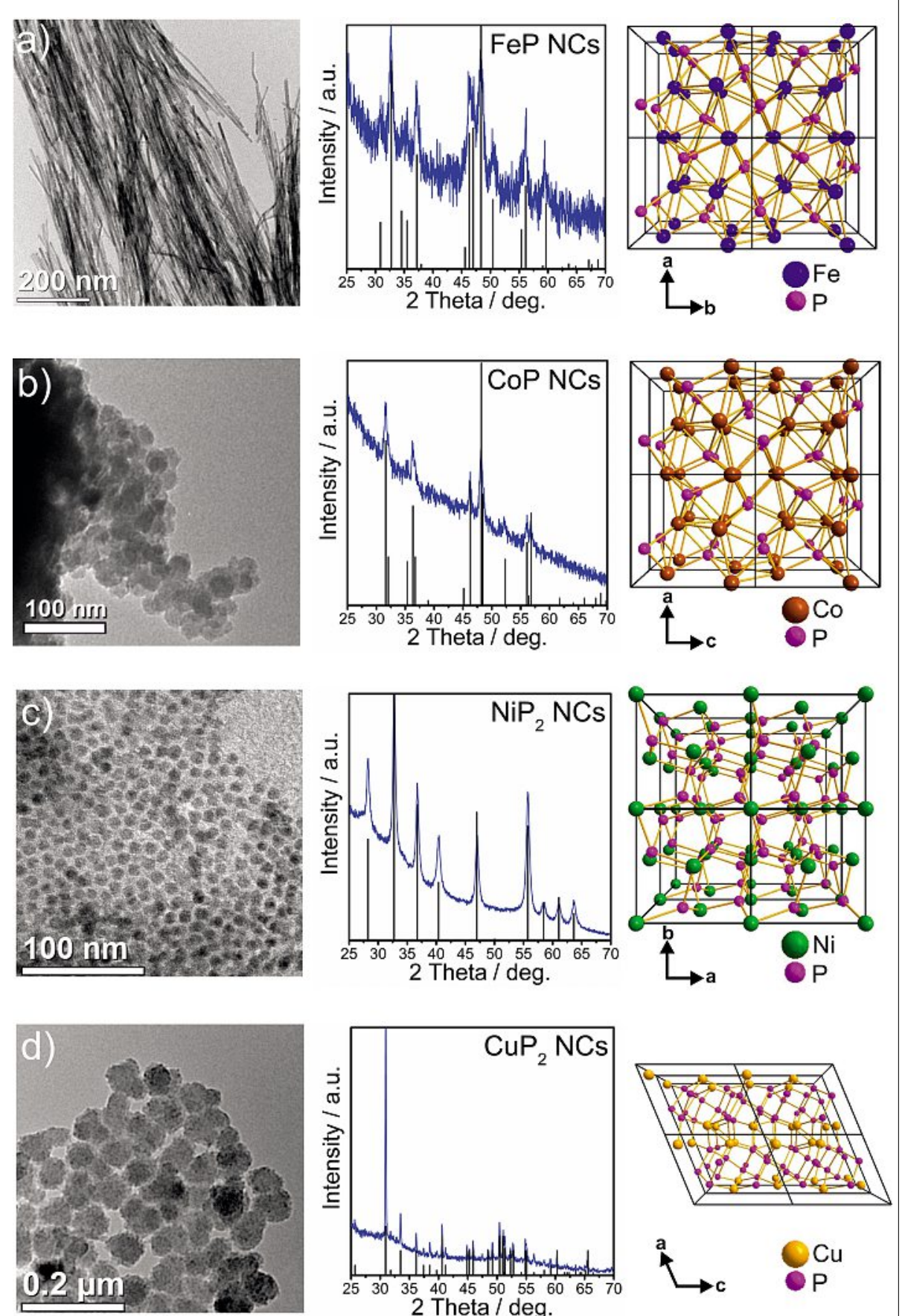

Fig. 1. Characterization of metal phosphide NCs. Transmission electron microscopy (TEM) images, X-ray diffraction (XRD) patterns and schematic representations of the crystal structures (from left to right) of $\mathrm{FeP}, \mathrm{CoP}, \mathrm{NiP}_{2}$ and $\mathrm{CuP}_{2} \mathrm{NCs}(\mathrm{a}-\mathrm{d})$. The XRD patterns are indexed according to the ICSD database: to orthorhombic FeP (PDF No.: 00-071-2262, space group Pna21 (33), a = 5.193 $\AA, b=5.792 \AA, c=3.099 \AA$ ) , orthorhombic CoP (PDF No.: 00-029-0497, space group Pnma (62), $a=5.077 \AA ⿻, b=3.281 \AA ̊, c=5.587 \AA$ ), cubic NiP 2 (PDF No.: 00-073-0436, space group Pa3 (205), $a=5.4706 \AA$ ) and monoclinic $\operatorname{CuP}_{2}$ (PDF No.: 00-076-1190, space group P21/c (14), $a=5.8004 \AA$, $\mathrm{b}=4.8063 \AA, c=7.5263 \AA$, $\beta=112.7^{\circ}$ ).

NiP 2 NCs, the capacities fell to below 600 $\mathrm{mAh} \mathrm{g}^{-1}$ after just the first 10 cycles, and faded to less than $400 \mathrm{mAh} \mathrm{g}^{-1}$ during subsequent cycling. Similar observations were made when testing the metal phosphide $\mathrm{NCs}$ in Li-ion half-cells (Fig. 2b). Due to the high surface area of the nanosized materials, low coulombic efficiencies (20$70 \%$ ) were obtained for the first cycle due to the irreversible decomposition of the electrolyte forming the solid electrolyte interface (SEI) (see Figs 2c and 2d). Notably, rather poor coulombic efficiencies of $92-95 \%$ for $\mathrm{Na}$-ion and $96-98 \%$ for $\mathrm{Li}-$ ion cells were obtained during subsequent cycles, indicating continuous deterioration and reformation of the SEI caused by pulverization of the electrode material.

Figs $2 \mathrm{e}$ and $2 \mathrm{f}$ show the galvanostatic charge and discharge voltage profiles for the first cycle for all tested metal phosphide NCs. For sodium ion storage, a desodia- tion plateau can be identified in all cases at $\sim 0.6 \mathrm{~V}$ vs. $\mathrm{Na}^{+} / \mathrm{Na}$, which is at the same potential as reported for the electrochemical reaction of red $\mathrm{P}$ with $\mathrm{Na}{ }^{[3 \mathrm{e}]}$ This implies that metal phosphides rather convert into elemental $\mathrm{P}$ and that cycling proceeds mainly by the reaction $\mathrm{P}+3 \mathrm{e}^{-}+3 \mathrm{Na}^{+} \leftrightarrow$ $\mathrm{Na}_{3} \mathrm{P}$, as has been suggested for FeP. ${ }^{[5]}$ In Li-ion half-cells, the majority of delithiation occurs at a potential of more than 1.0 $\mathrm{V}$ showing that metal phosphides are generally better suited as SIB anode materials due to lower voltages of desodiation.

\subsection{Comparison of FeP and $\mathrm{FeS}_{2}$ NCs as Anode Materials for Na-ion Batteries}

Clearly, from the prospects of low cost and low toxicity, iron-based sodium storage electrode materials are the most interesting candidates, in particular when the other chemical constituents of the compound comprise equally abundant elements such as phosphorus and sulfur. Hence, iron sulfides can be seen as a main alternative to phosphides. Similar difficulties with capacity fading might occur for $\mathrm{FeS}_{2}$ (pyrite) due to its large ( 280\%) volume expansion upon $\mathrm{Na}_{2} \mathrm{~S}$ formation. ${ }^{[10]} \mathrm{In}$ order to compare the electrochemical performance of $\mathrm{Fe}$ phosphides and sulfides, we synthesized pyrite $\mathrm{FeS}_{2} \mathrm{NCs}$ with sizes from $50-100 \mathrm{~nm}$ and tested them under the same conditions as the FeP NCs. The synthesis, characterization and electrochemical properties of $\mathrm{FeS}_{2} \mathrm{NCs}_{\text {have been }}$ detailed in our recent report. ${ }^{[11]}$ Assuming the formation of $\mathrm{Na}_{2} \mathrm{~S}, \mathrm{FeS}_{2} \mathrm{NCs}$ possess a theoretical maximum capacity of $894 \mathrm{mAh}$ $\mathrm{g}^{-1}$, similar to the value for FeP (926 mAh $\left.\mathrm{g}^{-1}\right)$. However, as can be seen in Fig. 3, the electrochemical performance of $\mathrm{FeS}_{2}$ and FeP NCs is in fact very different. Whereas FeP NCs show rapid capacity fading upon cycling, $\mathrm{FeS}_{2}$ NCs exhibit stable capacities of $\geq 800 \mathrm{mAh} \mathrm{g}^{-1}$ (near the theoretical value), clearly demonstrating that the identity of the anion in a conversion-type electrode material plays a critical role in determining its electrochemical properties. The only relevant previous investigation of $\mathrm{FeP}$ as a SIB anode material is the recent report by Li et al.;5] in that work, anodes prepared by ball-milling FeP showed much faster capacity fading, from $460 \mathrm{mAh} \mathrm{g}^{-1}$ to $\sim 200 \mathrm{mAh} \mathrm{g}^{-1}$ within 40 cycles at a current of $50 \mathrm{~mA} \mathrm{~g}^{-1}$. Compared to FeP NCs, the only obvious drawback of $\mathrm{FeS}_{2} \mathrm{NCs}_{\text {is }}$ the higher desodiation potential (Figs $3 \mathrm{~b}$ and $3 \mathrm{c})$, that is, however, well compensated by good capacity retention.

\section{Conclusion}

In conclusion, we have prepared NCs of $\mathrm{FeP}, \mathrm{CoP}, \mathrm{NiP}_{2}$ and $\mathrm{CuP}_{2}$ using colloi- 


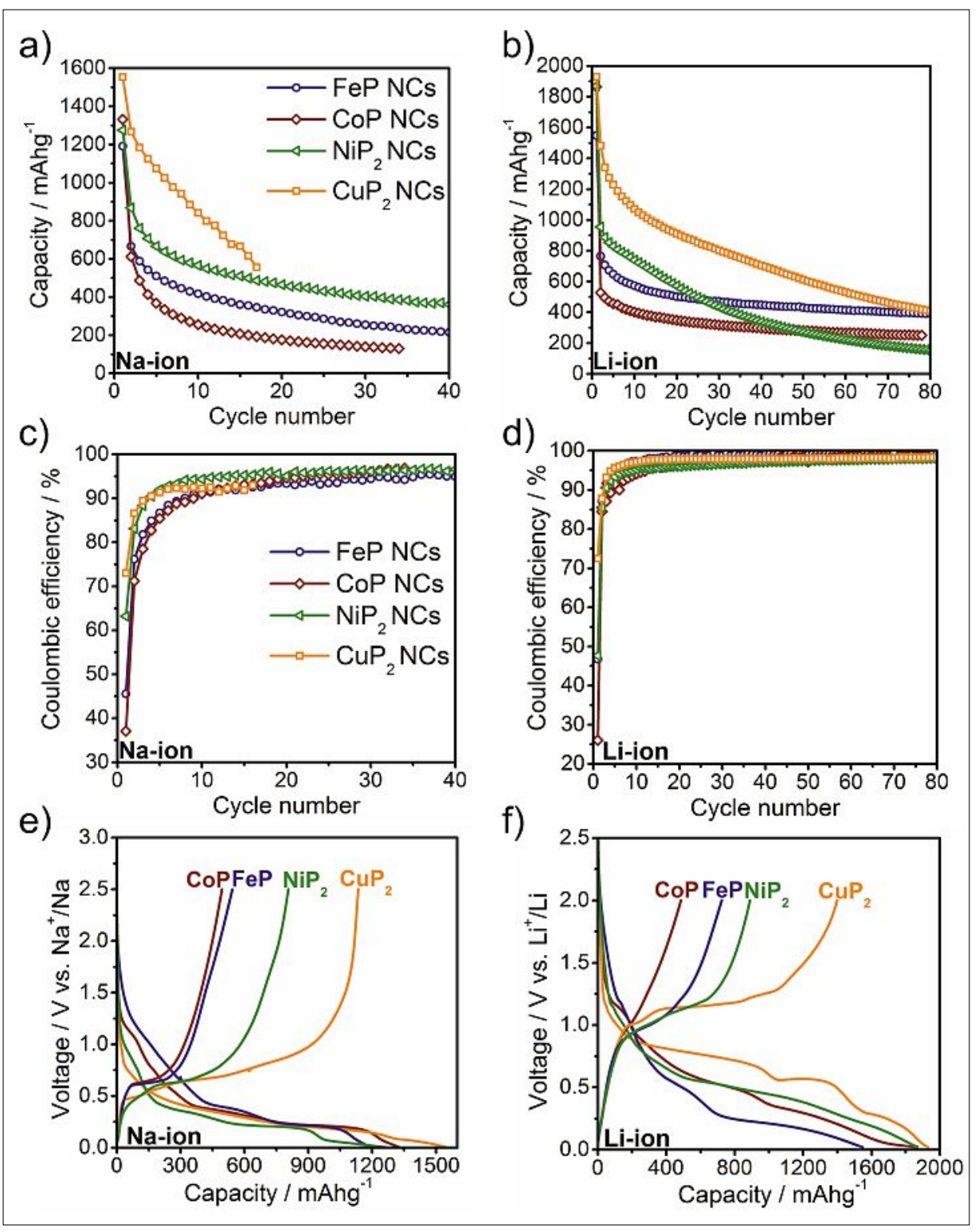

Fig. 2. Electrochemical performance of metal phosphide nanocrystals. Galvanostatic cycling of metal phosphide NCs in Na-ion (a) and Li-ion half-cells (b) with the respective coulombic efficiency plots (c, d). Galvanostatic charge and discharge curves for the first cycle for $\mathrm{Na}$-ion (e) and Li-ion (f) half-cells. Electrodes were composed of $63.75 \%$ metal phosphide NCs, $21.25 \%$ CB and $15 \% \mathrm{CMC} 1 \mathrm{M} \mathrm{NaClO}_{4}$ in PC with $10 \%$ FEC served as the electrolyte for $\mathrm{Na}$-ion and $1 \mathrm{M} \mathrm{LiPF}_{6}$ in EC:DMC (1:1) for Li-ion half-cells. Galvanostatic cycling tests were carried out with a current of $100 \mathrm{~mA} \mathrm{~g}^{-1}$ in the potential range of $0.02-2.5 \mathrm{~V}$ for Na-ion and $300 \mathrm{~mA} \mathrm{~g}^{-1}$ in the potential range of $0.02-2.0 \mathrm{~V}$ for Li-ion half-cells.

dal synthesis methods. Motivated by their high theoretical capacities, the low electrochemical potentials needed for the anodic side of the battery, and the high natural abundance of their constituting elements, we explored the potential of these nanomaterials as SIB anode materials. We also compared their sodium storage properties with that of lithium. We find that with conventionally formulated electrodes (by mixing with amorphous carbon and watersoluble binders), metal phosphide NCs deliver high sodium capacities but exhibit low capacity retention upon cycling. The direct comparison of $\mathrm{FeP}$ and $\mathrm{FeS}_{2}$ as SIB anode materials indicates the much better cyclability of the latter. We thus conclude that metal phosphides are inherently less stable than their corresponding sulfides and this instability is a combined effect of large volumetric changes and phosphorusspecific processes, such as the reactivity of $\mathrm{Na}_{3} \mathrm{P}$ towards the electrolyte. ${ }^{[3 \mathrm{c}]}$ Further progress towards high performance phosphide-based electrodes is expected to result from smart electrode engineering by designing secondary structures in which the metal phosphide NPs are encapsulated into conductive carbons, ${ }^{[12]}$ thereby eliminating the direct large-area contact with the electrolyte. Furthermore, a sensible choice of the electrolyte and electrolyte additives might enable the higher stability of the SEI layer in future studies.

\section{Acknowledgements}

This work was financially supported by the Swiss Federal Commission for Technology and Innovation (CTI, Project Nr. 14698.2 PFIW-IW), CTI Swiss Competence Centers for Energy Research (SCCER, 'Heat and Electricity Storage'), SNF Ambizione Energy grant (PZENP2_154287) and ETH Zürich (Grant Nr. ETH-56 12-2). Electron microscopy was performed at the Empa Electron Microscopy Center. We thank Dr. Nicholas Stadie for reading the manuscript.

Received: August 21, 2015

[1] a) R. Van Noorden, Nature 2014, 507, 26; b) V. Palomares, P. Serras, I. Villaluenga, K. B. Hueso, J. Carretero-Gonzalez, T. Rojo, Energy Environ. Sci. 2012, 5, 5884; c) M. D. Slater, D. Kim, E. Lee, C. S. Johnson, Adv. Funct. Mater. 2013, 23, 947; d) H. Pan, Y.-S. Hu, L. Chen, Energy Environ. Sci. 2013, 6, 2338; e) N. Yabuuchi, K. Kubota, M. Dahbi, S. Komaba, Chem. Rev. 2014, 114, 11636.

[2] a) P. Ge, Solid State Ionics 1988, 28, 1172; b) S. Komaba, Y. Matsuura, T. Ishikawa, N. Yabuuchi, W. Murata, S. Kuze, Electrochem. Commun. 2012, 21, 65; c) L. D. Ellis, B. N. Wilkes, T. D. Hatchard, M. N. Obrovac, J. Electrochem. Soc. 2014, 161, A416.

[3] a) J. Qian, X. Wu, Y. Cao, X. Ai, H. Yang, Angew. Chem. Int. Ed. 2013, 52, 4633; b) Y. Kim, Y. Park, A. Choi, N.-S. Choi, J. Kim, J. Lee, J. H. Ryu, S. M. Oh, K. T. Lee, Adv. Mater. 2013, 25, 3045; c) N. Yabuuchi, Y. Matsuura, T. Ishikawa, S. Kuze, J.-Y. Son, Y.-T. Cui, H. Oji, S. Komaba, ChemElectroChem 2014, 1, 580; d) W.-J. Li, S.-L. Chou, J.-Z. Wang, H.-K. Liu, S.-X. Dou, Nano Lett. 2013, 13, 5480; e) M. Walter, R. Erni, M. V. Kovalenko, Sci. Rep. 2015, 5; f) J. Song, Z. Yu, M. L. Gordin, S. Hu, R. Yi, D. Tang, T. Walter, M. Regula, D. Choi, X. Li, A. Manivannan, D. Wang, Nano Lett. 2014, 14, 6329; g) Y. Zhu, Y. Wen, X. Fan, T. Gao, F. Han, C. Luo, S.-C. Liou, C. Wang, ACS Nano 2015, 9, 3254.

[4] a) M. F. Oszajca, M. I. Bodnarchuk, M. V. Kovalenko, Chem. Mater. 2014, 26, 5422; b) N. Liu, Z. Lu, J. Zhao, M. T. McDowell, H.W. Lee, W. Zhao, Y. Cui, Nat. Nanotechnol. 2014, 9, 187; c) A. Magasinski, P. Dixon, B. Hertzberg, A. Kvit, J. Ayala, G. Yushin, Nat. Mater. 2010, 9, 353; d) C. K. Chan, R. N. Patel, M. J. O'Connell, B. A. Korgel, Y. Cui, ACS Nano 2010, 4, 1443; e) P. G. Bruce, B. Scrosati, J.-M. Tarascon, Angew. Chem. Int. Ed. 2008, 47, 2930; f) M. R. Palacin, Chem. Soc. Rev. 2009, 38, 2565; g) K. Kravchyk, L. Protesescu, M. I. Bodnarchuk, F. Krumeich, M. Yarema, M. Walter, C. Guntlin, M. V. Kovalenko, J. Am. Chem. Soc. 2013, 135, 4199; h) M. He, K. Kravchyk, M. Walter, M. V. Kovalenko, Nano Lett. 2014, 14, 1255; i) M. He, M. Walter, K. V. Kravchyk, R. Erni, R. Widmer, M. V. Kovalenko, Nanoscale 2015, 7, 455; j) J. Liu, Y. Wen, P. A. van Aken, J. Maier, Y. Yu, Nano Lett. 2014, 14, 6387; k) A. Jahel, C. M. Ghimbeu, L. Monconduit, C. Vix-Guterl, Adv. Energy Mater. 2014, 4, DOI: 10.1002/aenm.201400025.

[5] W.-J. Li, S.-L. Chou, J.-Z. Wang, H.-K. Liu, S.X. Dou, Chem. Commun. 2015, 51, 3682.

[6] D. V. Talapin, C. B. Murray, Science 2005, 310, 86.

[7] a) A. M. Chockla, K. C. Klavetter, C. B. Mullins, B. A. Korgel, Chem. Mater. 2012, 24, 3738; b) V. Etacheri, O. Haik, Y. Goffer, G. A. Roberts, I. C. Stefan, R. Fasching, D. Aurbach, Langmuir 2011, 28, 965; c) S. Komaba, T. Ishikawa, N. Yabuuchi, W. Murata, A. Ito, Y. Ohsawa, ACS Appl. Mater. Interfaces 2011, 3, 4165; d) L. O. 


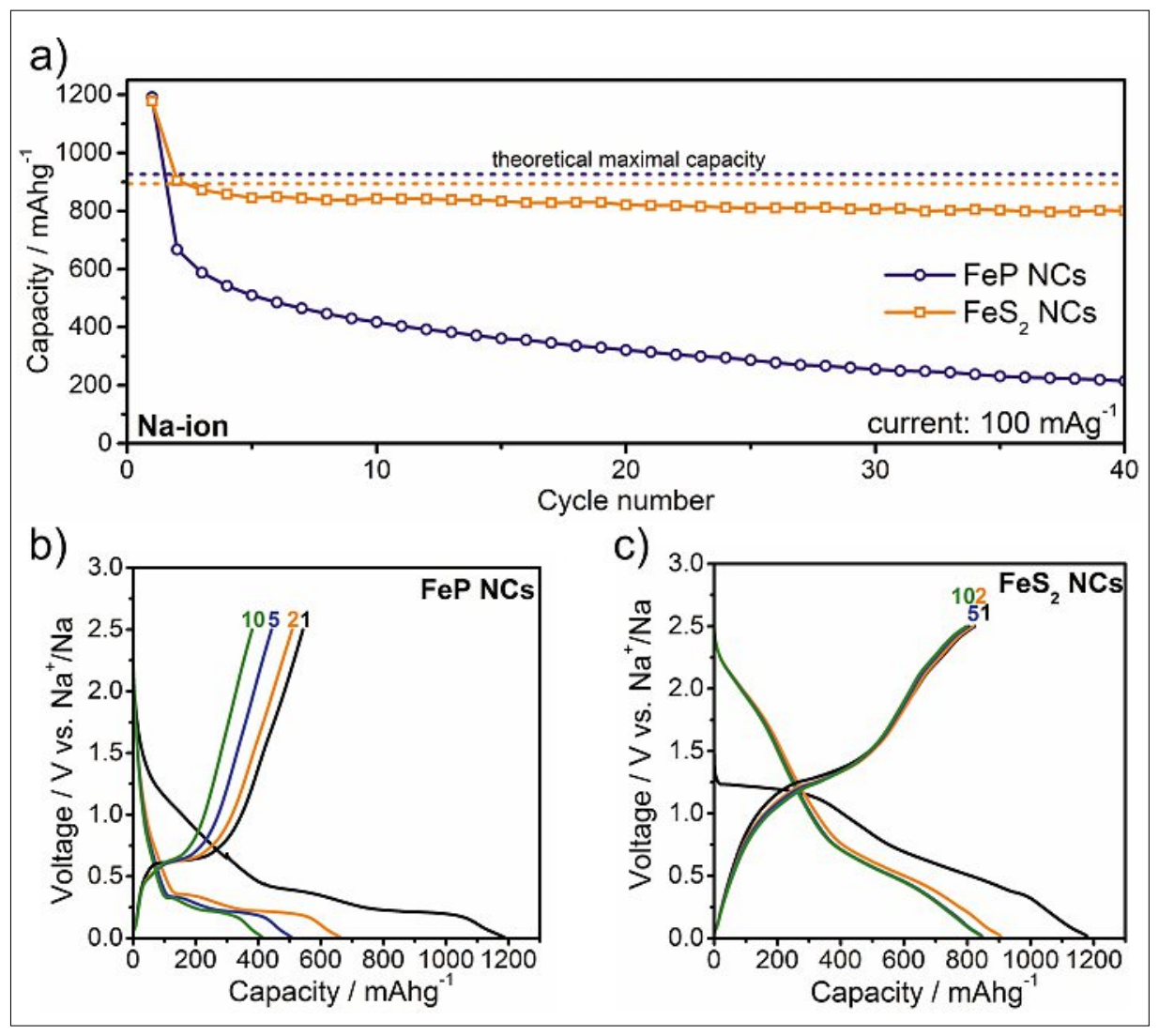

Fig. 3. Comparison of the electrochemical performance of $\mathrm{FeP}$ and $\mathrm{FeS}_{2} \mathrm{NCs}$. Galvanostatic cycling of $\mathrm{FeS}_{2}$ and $\mathrm{FeP}$ in Na-ion half-cells (a) and the respective charge/discharge curves (b, c). Galvanostatic cycling tests were carried out with a current of $100 \mathrm{~mA} \mathrm{~g}^{-1}$ in the potential range of $0.02-2.5 \mathrm{~V}$.
Vogt, M. El Kazzi, E. Jämstorp Berg, S. Pérez Villar, P. Novák, C. Villevieille, Chem. Mater. 2015, 27, 1210.

[8] C. Qian, F. Kim, L. Ma, F. Tsui, P. Yang, J. Liu, J. Am. Chem. Soc. 2004, 126, 1195.

[9] E. J. Popczun, J. R. McKone, C. G. Read, A. J. Biacchi, A. M. Wiltrout, N. S. Lewis, R. E. Schaak, J. Am. Chem. Soc. 2013, 135, 9267.

[10] F. Klein, B. Jache, A. Bhide, P. Adelhelm, Phys. Chem. Chem. Phys. 2013, 15, 15876.

[11] M. Walter, T. Zund, M. Kovalenko, Nanoscale 2015, 7, 9158 .

[12] a) X. Ji, K. T. Lee, L. F. Nazar, Nat. Mater. 2009 , 8,500 ; b) X. W. Lou, C. M. Li, L. A. Archer, Adv. Mater. 2009, 21, 2536; c) H. Zhang, X. Yu, P. V. Braun, Nat. Nanotechnol. 2011, 6, 277; d) Y. Yu, L. Gu, C. Wang, A. Dhanabalan, P. A. van Aken, J. Maier, Angew. Chem. Int. Ed. 2009, 48, 6485; e) N. Liu, H. Wu, M. T. McDowell, Y. Yao, C. Wang, Y. Cui, Nano Lett. 2012, 12, 3315. 